\title{
PARÂMETROS CONCEITUAIS À ESTRATÉGIA PEDAGÓGICA NO CONTEXTO DE METODOLOGIA ATIVA
}

\author{
Conceptual parameters for pedagogical strategy in the context of an active methodology
}

\author{
João Ferreira Sobrinho Junior. ${ }^{1}$ \\ Cristina de Cássia Pereira Moraes $^{2}$
}

\section{http://dx.doi.org/10.52641/cadcaj.v7i1.565}

\begin{abstract}
RESUMO: No contexto contemporâneo, percebe-se a intencionalidade de ações educativas que visem implementar métodos inovadores e diversificados, a partir de estratégias pedagógicas diversas. Entretanto, os parâmetros conceituais que podem subsidiar tais estratégias pedagógicas, por vezes ainda não estão bem claros ou estabelecidos aos atores educacionais. Este artigo se propôs a apresentar parâmetros conceituais que possam subsidiar estratégias pedagógicas diversas no contexto de metodologia ativa. Com vistas a responder esse cenário, como percurso metodológico se dispôs de pesquisa documental e bibliográfica, para o levantamento, coleta e análise dos dados de forma qualitativa. E como resultado da pesquisa identificamos seis parâmetros conceituais: O aprendizado ativo dos alunos; A perspectiva de inovação pedagógica para o ensino, utilizando-se ou não de tecnologias digitais; A apropriação da informação se dê de forma atrativa; A posição mediadora do professor frente ao ensino; A interação entre os alunos e o professor; e, a reflexão crítica da realidade. Concluímos, que estes parâmetros conceituais podem ser utilizados subsidiariamente à construção e desenvolvimento de estratégias pedagógicas no contexto de metodologia ativa, tendo em vista, essa ser uma necessidade advinda dos dias atuais, ao qual se estimula métodos inovadores e diversificados à ação educativa.
\end{abstract}

Palavras-chave: Metodologia ativa. Estratégia Pedagógica. Lúdico.

ABSTRACT: In the contemporary context, one can notice the intentionality of educational actions that aim to implement innovative and diversified methods, based on various pedagogical strategies. However, the conceptual parameters that can support such pedagogical strategies are sometimes not yet clear or established to the educational actors. This article aims to present conceptual parameters that can subsidize diverse pedagogical strategies in the context of active methodology. In order to respond to this scenario, the methodological approach used was documentary and bibliographic research, for the survey, data collection and data analysis in a qualitative way. As a result of the research we identified six conceptual parameters: The active learning of the students; The perspective of pedagogical innovation for teaching, using or not digital technologies; The appropriation of the information takes place in an attractive way; The mediating position of the teacher facing the teaching; The interaction between the students and the teacher; and, the critical reflection of reality. We conclude that these conceptual parameters can be used subsidiarily to the construction and development of pedagogical strategies in the context of active methodology, considering that this is a necessity arising from the present day, which stimulates innovative and diversified methods to the educational action.

Keywords: Active methodology. Pedagogical strategy. Playful.

\footnotetext{
${ }^{1}$ Doutorando em História pela Universidade Federal de Goiás (UFG). Orcid: https://orcid.org/0000-0003-37569797. E-mail: joffersoju07@,hotmail.com

2 Doutora em História das Ideias pela Universidade Nova de Lisboa - Portugal. Professora Associada da Universidade Federal de Goiás (UFG). ORCID: https://orcid.org/0000-0001-8767-7070. E-mail: cristinadecassiapmoraes@gmail.com
} 


\section{NOTAS INTRODUTÓRIAS}

Contemporaneamente, temos a predominância do ensino tradicional no Brasil. Esse modelo se baseia principalmente na transmissão unilateral do conteúdo pelo professor, ao qual instiga primordialmente a memorização para a aprendizagem. Nesse contexto, o aluno se posta como alheio à construção do conhecimento, se portando como um receptáculo da informação que lhe é repassada por um único caminho, o professor.

O consenso da eficácia desse modelo tradicional é questionado já a algum tempo, pois a posição de inércia do aluno e o de detentor da informação pelo professor, torna o ensino mecânico e sem um diálogo necessário à construção conjunta do conhecimento. A partir desses questionamentos quanto à eficácia do ensino tradicional, modelos alternativos foram pensados no sentido de trazer um maior dinamismo, atratividade e criatividade às aulas, sob o prisma de uma metodologia ativa.

A metodologia ativa não é um conceito pronto ou fixo, pois isso poderia suscitar problemáticas já presentes no ensino tradicional, como por exemplo, o ensino ser considerado chato e maçante. Em vista a isso, esta se propõe em ser dinâmica e flexível, para assim tornar-se desafiadora, instigadora, crítica e atraente. Esses aspectos de metodologia ativa são fundamentados em autores que corroboram tal pensamento como Peixoto (2016), Bartolomeu, Silva e Lozza (2017), Borges e Alencar (2014), Pereira (2012) e Freire (2015).

$\mathrm{Na}$ execução de sua prática docente, o professor deve se planejar de forma a construir um plano ao qual apresentará aos estudantes o conteúdo preestabelecido em determinado currículo escolar. No entanto quanto à forma de se transmitir essas informações, o professor possui - na maioria das vezes - discricionariedade e sim sendo, pode escolher sob um modo mais tradicional de ensino ou trazer a metodologia ativa para esse cenário. Nesse sentido, se fazem usos de estratégias pedagógicas para que essa transmissão se estabeleça.

Essas estratégias não são baseadas em recurso/ferramenta utilizada na prática cotidiana do professor, ou mesmo na forma como o aluno manuseia esse instrumento educativo. E sim, é estabelecida a partir de um processo intencional no contexto de uma ação educativa, seja ela provinda de um método tradicional ou ativo, conforme entendimento desta pesquisa. Entendimento esse, baseado em autores como Carolei, Bruno e Rocha (2017), Martins, Giraffa e Lima (2018), Santos e Kelman (2007) e Tacca (2014).

Essas estratégias pedagógicas são diversas e podem ser mescladas ou refinadas, de acordo com o contexto e o ambiente dado, muito embora, em seus fundamentos nos deparamos com conceitos que são balizadores destas. Esses fundamentos que lhes servem de diretrizes, podem facilitar os atores do contexto escolar - principalmente aqueles que estão no chão da escola, como 
os professores, coordenadores e mesmo os alunos - a estabelecerem a partir destes, a construção e implementação de estratégias pedagógicas ímpares e renovadas de estímulo e sopro de conhecimento. Temos então que a esses fundamentos, denominaremos: parâmetros conceituais.

Desse modo, no contexto contemporâneo, percebe-se que ao se investir em métodos inovadores e diversificados, os estudantes poderão ter maior interesse pelas aulas, melhorando seu aproveitamento dos conteúdos estudados. E para que isso torne-se mais factual - a partir de estratégias pedagógicas diversas - se faz necessário que o "professor mude suas práticas pedagógicas procurando adequar-se ao perfil da clientela atendida" (SIQUEIRA; QUIRINO, 2012, p. 6-7). Nessa problemática posta, suscitou-se a questão investigativa que norteou nosso percurso metodológico: Quais parâmetros conceituais podemos apresentar com fins a subsidiar estratégias pedagógicas no contexto de metodologia ativa?

Os caminhos metodológicos desta pesquisa versarão com base na abordagem qualitativa sob o viés bibliográfico e documental. Esses dois tipos são semelhantes, mas se diferenciam devido à natureza de suas fontes, pois segundo Gil (2002) enquanto na pesquisa documental não há um olhar de fora, avaliativo quanto ao tratamento de suas informações como por exemplo cartas pessoais, diários, regulamentos e ofícios, dentre outros. De outro lado, a pesquisa bibliográfica se fundamenta em materiais que foram revisados quanto ao seu conteúdo, como por exemplo livros e artigos científicos.

Ao abordarmos acerca da coleta, análise e discussão dos dados, em princípio fizemos uma explanação sobre questões relativas a estratégia pedagógica, como conceitos e fundamentos também chamados de parâmetros conceituais, e após, traçamos considerações sobre metodologia ativa. E em um segundo momento, ao identificarmos esses parâmetros conceituais, verificarmos se estes estão sob o contexto de metodologia ativa e assim, alcançarmos o objetivo desta pesquisa.

O objetivo desta pesquisa é apresentar parâmetros conceituais que possam subsidiar estratégias pedagógicas diversas no contexto de metodologia ativa. Pois, consideramos que tais parâmetros conceituais sob o viés do método ativo, podem contribuir substancialmente à construção e o desenvolvimento de estratégias pedagógicas mais desafiadoras, instigadoras, atraentes e criativas para o estudante.

\section{OLHARES SOBRE ESTRATÉGIA PEDAGÓGICA E A METODOLOGIA ATIVA}

Hodiernamente, levantam-se discussões dentro do contexto escolar que permeiam a predominância do ensino baseado na mera transmissão do conteúdo, em prol de outros modelos que possam suscitar maior atratividade. Esses modelos buscam inserir o aluno como centro do ensino, uma vez que se ater ao livro didático e ao calendário da escola pode tornar a aula chata e enfadonha, resultando em alunos dispersos e sem concentração no conteúdo apresentado. 
À vista disso, em nossos tempos é necessário um olhar sobre esse problema e buscar soluções através daqueles que estão inseridos na conjuntura em questão, tendo em vista que o principal foco dentro do contexto escolar, é a ação educativa. Sendo assim, os atores educacionais devem unir esforços para propiciar um ensino que favoreça a autonomia discente, buscando com isso, uma interação mais profícua e harmoniosa entre os indivíduos integrantes desse meio, com fins a beneficiar o ambiente da aprendizagem, seja ela presencial ou não.

Logo, a partir do cenário exposto acima acerca da percepção entre alunos e professores sobre uma metodologia mais atraente, instigadora e inovadora, percebe-se que para tal é necessário que se procure respostas que se contrapõem ao ensino tradicional. Esse ensino que no geral é basicamente focado em uma transmissão de conteúdo, onde decorar - não que esse seja um problema em si, mas sua utilização como metodologia única, sim - é a base para o desenvolvimento do conhecimento e a apropriação da informação. Ademais, nesse ensino tradicionalista, o aluno se porta de forma passiva, configurando assim, um ensino centrado no professor.

Isto posto, dialogaremos por questões que possam contribuir no debate sobre parâmetros conceituais que possibilitem subsidiar estratégias pedagógicas diversas no contexto de metodologia ativa, e dessa forma, fazer emergir alguns pontos de destaque à interação construtiva entre o estudante e o professor, com fins à apropriação do conhecimento.

\subsection{Estratégia Pedagógica: Questões que a Orbitam}

Ao se trazer à tona a estratégia pedagógica, é importante traçar os pensamentos de diversos autores sobre o seu conceito. Segundo Carolei, Bruno e Rocha (2017) é importante primeiramente se estabelecer as distinções entre recurso didático, atividades e estratégia pedagógica. Para eles, os primeiros são materiais que foram construídos para o processo de ensino, e citam o livro, textos ou mesmo jogos. O segundo são as propostas de ações dos alunos, ou seja, o que irão fazer com esses materiais, a partir de um modelo pensado intencionalmente para aquele contexto. $\mathrm{O}$ terceiro por fim, é a estratégia pedagógica. Ela consiste em se pensar as sequências da prática docente e “em todas as interações entre a ação do professor ou mediador e as atividades propostas aos alunos, incluindo as formas de utilização dos recursos” (p. 2). Ou seja, não são apenas um recurso ou uma atividade, e sim, são caminhos a serem percorridos e que darão um sentido a esses recursos ou atividade, sob um determinado planejamento.

De outro modo, Martins, Giraffa e Lima (2018) destacam cada verbete separadamente, pois, de um lado tratam a estratégia como um conjunto de potenciais pedagógicos que impactam de forma promissora, o processo de ensino e aprendizagem. De outro, o termo pedagógico é pensado no sentido ao qual esta estratégia deva ser articulada e organizada, com fins a produzir as 
condições e os resultados propícios ao aprendizado do estudante. E por fim, conceituam estratégia pedagógica como sendo os "objetivos e metas e das escolhas teóricas e metodológicas possíveis nas ações ou sequências didáticas que envolvem os processos de ensino e de aprendizagem” (p. 2).

De acordo com o defendido por Santos e Kelman (2007), deve-se pensar a estratégia pedagógica não apenas com o objetivo de despertar uma vontade de aprender no aluno, e sim, deve-se ir mais além, ao considerar o que o realmente é internalizado pelo aluno sobre o que ele está aprendendo, como também o que ele pensa sobre todo o processo educacional. Pois, de outra forma, se ater apenas na criação ou invenção de uma nova técnica que simplesmente prenda a atenção do aluno para que o professor tenha sucesso em transmitir o conteúdo, é apenas atrelar a estratégia pedagógica a um recurso externo ao aluno, refletindo assim, na busca por uma "atenção sem pensamento, sem significação" (p. 4).

Nesse mesmo direcionamento, Tacca (2014) destaca que as estratégias pedagógicas devem ser percebidas pelo professor, sob a ótica do desejo e interesse do aluno. Dessa forma, esse processo dialógico de comunicação, deve assentar um espaço que permita que esses atores interajam a partir de seus conhecimentos, atitudes, dúvidas e angústias, pois, a escola deve ser significativa para esses aprendizes. Além disso, os espaços formais e não-formais de aprendizagem, devem se unir ao sujeito e ao conhecimento, concretizando assim o caminho de que a estratégia pedagógica se "orienta para a relação social que passa a ser uma condição para a aprendizagem, pois só ela dá possibilidade de conhecer o pensar do outro e interferir nele” (p. 48).

Por fim, a partir dos conceitos apresentados acima, consideramos para este trabalho que a estratégia pedagógica não se pauta apenas em um recurso/ferramenta utilizado pelo professor ou como o aluno se utiliza desse instrumento. E sim, é voltado a um processo que se estabelece desde o planejamento até a execução intencional de uma ação educativa, partir de um método préestabelecido, seja ele tradicional ou ativo.

Após conceituarmos a estratégia pedagógica para este trabalho, é relevante traçarmos questões que orbitam esse conceito, com vistas a identificarmos e por fim, apresentarmos os parâmetros conceituais que possam subsidiar estratégias pedagógicas diversas.

Primeiramente podemos tratar de autonomia do aluno, a qual pode contribuir no seu protagonismo. No que tange a autonomia do aluno em relação à educação já fora destacado acerca do ensino tradicional a postura passiva dos alunos, trazendo com isso um fluxo unilateral da informação. E em conta dessa passividade, ele não se manifesta e assim, também não pode ser protagonista ou apresentar-se de forma crítica ao que é apresentado.

De outro lado, teríamos a autonomia deste mesmo aluno a partir de um método mais participativo, trazendo com isso seu protagonismo, tal pensamento é corroborado por Berbel 
(2011) e ainda o estende como necessário para o futuro profissional do aluno sob uma postura pedagógica e não de controle pelos professores. Assim sendo, a autonomia do aluno deve ser amparada por postura contributiva do professor, estimulando-o a refletir sobre as questões que lhe são apresentadas.

Nesse direcionamento, Jófili (2002) nos reporta que o professor deve assegurar um ambiente no qual os alunos reconheçam suas ideias, aceitem as ideias do outro sob seus diferentes pontos de vista, e além disso possam avaliar comparativamente essas ideias com a teoria apresentada pelo professor. Assim, podemos perceber a importância do docente na autonomia e protagonismo do aluno. Pois, quando dizemos autonomia não afirmamos que o aluno irá estudar sozinho sem interferência de ninguém, e sim através do professor que o estimularia por meio da motivação e de explicações para a realização de atividades individuais ou em grupo, trazendo com isso maiores possibilidades de autonomia e protagonismo em sua aprendizagem.

Essa autonomia do aluno pode ser mais aflorada a partir de uma pedagogia inovadora com ou sem o uso de tecnologias digitais. Tavares (2019) em sua pesquisa, realiza um levantamento bibliográfico sobre a inovação pedagógica e traz em suas percepções que seus conceitos partem de quatro categorias: a inovação como algo positivo; a inovação como sinônimo de mudança e reforma educacional; a inovação como modificação de propostas curriculares; e por fim, a inovação como alteração de práticas educacionais costumeiras em um grupo social.

Segundo Mitrulis (2002), para ser considerada inovação uma determinada invenção, descoberta, criação ou assemelhado, deve ter uma ratificação pública, ou seja, não pode ser apenas sob a ótica do autor que tal inovação será realmente inovadora, pois esses atos de "descobrir, inventar e criar são atos singulares e primeiros, estão na origem e servem de referência, modelo e inspiração para transformar a realidade" (p. 230).

Por fim, Messina (2001) nos apresenta a problematização de que a inovação pedagógica ao ser posta como o centro do ensino, esta passa a ser conservadora, e assim se precisa romper e discutir sua real mudança para própria educação. Essa mudança deve partir da discussão/diálogo sob os princípios de sua própria razão de existir ou mesmo pra quem este foi pensado e posto em prática essa inovação.

Assim, percebe-se a complexidade da inovação pedagógica para se tornar em uníssono, tanto sob os aspectos da própria compreensão do que seria esse conceito, passando pelo seu aceite perante a sociedade, como também a discussão sobre sua pertinência frente as reais situações sociais, tangenciando em questões sobre para quem realmente interessa essa inovação ou não, no contexto educacional. 
Temos então que uma pedagogia inovadora não deve se ater aos tempos do ensino tradicional, pois se é tradicional não necessariamente é inovador, temos então um dilema. Logo é melhor rompermos e traçarmos novos caminhos que tragam a alegria, a instigação e desafio que podemos obter pelo uso do lúdico no ensino. Acerca do conceito de lúdico vários autores discorrem sobre o tema. Kishimoto (1996) aborda que com a utilização desse tipo de atividade, o aluno é estimulado a desenvolver sua criatividade e assim, assimilando melhor a informação que lhe é apresentada.

Autores consagrados no campo educacional também discorrem sobre o tema, Vygotsky (1984) apresenta que o simbolismo imaginário na criança é mais fortemente agregado ao aprendizado do que o real. E para Piaget, segundo pondera Pimenta (2011), as atividades lúdicas estão vinculadas ao desenvolvimento da função simbólica, pois "durante o desenvolvimento da criança, surgem novos e diversos símbolos lúdicos que determinam à evolução do jogo simbólico" (p. 14).

E por fim, Soares (2010) traça um paralelo da atividade lúdica com a alegria e o prazer do próprio jogo, e isso independente da classe social pois é algo inato ao ser humano, uma vez que além de auxiliar em seu desenvolvimento físico, intelectual, emocional, “contribui em sua própria construção enquanto sujeito social” (p. 18).

Em suma, a partir desses conceitos, podemos direcionar o lúdico sob diversas óticas. Dentre essas, partiremos da indicação de que ele é uma atividade em que o ato do brincar, do jogar, não deve ser visualizado apenas pela ótica em si mesmo, e sim como uma relação intrínseca entre o aprendizado e o ato lúdico, com a finalidade de se obter os resultados esperados. Sob outro aspecto, o lúdico traz a possibilidade de ser uma fonte importante para o desenvolvimento do educando, estimulando seu desenvolvimento cognitivo e somático.

Além disso, o lúdico contribui para socialização do estudante, pois ao praticá-lo, se compete e se envolve por meio das relações sociais ali postas entre os indivíduos partícipes dessa atividade ou orientadores da mesma. Ademais, o sujeito estará em contato direto com suas emoções e sentimentos, e terá possibilidades de controle sobre si próprio, ao se encontrar em situações de frustação ou de vitória no decorrer da atividade lúdica, através das ações que se desenrolam e se propõem por meio desta (HUIZINGA, 2008).

O lúdico traz alegria, instigação e desafio pois brincar não tem idade. No entanto, esse contexto pode ser transformado em obrigação apenas pelo modo como o jogo é conduzido. Assim, no campo da educação, o professor deve ser um condutor exímio para melhor apropriação do conteúdo pelo estudante e assim, os atores envolvidos devem ter a compreensão de que o professor 
é o mediador/auxiliador e não, o único meio possível de conexão entre o aluno e a informação que lhe é apresentada.

Em primeira ótica, Neves (2014), conclama para a mudança nos moldes de docência no século XXI, e assim os professores tem que se adequar também a essa nova realidade. Essa realidade na qual as tecnologias digitais estão presentes possibilitam novas oportunidades de vivência ao aprendizado e isso reflete em um modo de trabalho diferente, uma vez que a sociedade mudou, então os processos de se buscar/mediar o conhecimento também se alterou e dessa forma “os professores necessitam mudar" (p. 887).

Ainda nesse sentido, Inocêncio e Cavalcanti (2007), reafirmam que trazer o centro do aprendizado para o aluno não deve ser encarado como uma depreciação do papel do professor, levando em conta este ser figura essencial para o ensino ao "criar, estruturar e animar experiências de aprendizagem" (p. 3). Destaca-se então, o papel relevante do professor que se perpassa também pela harmonia e o aprendizado afetivo que depreende de um processo de ensino onde cada ator, sabe e executa sua função para ganho de todos.

Tal pensamento é corroborado por Oliveira (2010) ao dizer que o ato de ensinar é um ato de facilitar a aprendizagem dos estudantes e os tornar elementos ativos e corresponsáveis pelo seu aprendizado, e para que isso se estabeleça é necessário que o professor se desprenda do centro e orbite na trilha do conhecimento junto com os alunos.

E assim com harmonia e afetividade, o professor consegue não somente mediar, mas também fazer o aluno refletir propiciando com isso torna-lo um sujeito ativo na sociedade ao qual está inserido, pois é incongruente o professor exigir criticidade ao estudante se ele mesmo é "mecanicamente memorizador, e muito mais um repetidor de frases e de ideias inertes do que um desafiador" (FREIRE, 2015, p. 29).

Logo, podemos ver o professor como um mediador e que de forma alguma seria menosprezado por ser tal, pois constitui-se no elo entre o aluno e a informação, e com isso, contribui substancialmente no processo de aprendizagem deste ao propiciar a harmonia e o aprendizado afetivo, muito embora não deixando de lado o seu papel de instigador e construtor crítico por meio do seu ensinar.

Essa mediação deve ser espargida por todo o contexto desse ensino e ainda alimentar no aluno a interação e a colaboração mútua no contexto escolar, trazendo com isso resultados positivos e significativos. É primordial que o aluno se integre colaborativamente e interaja com o professor e os colegas, e essa premissa é partilhada por Anastasiou e Alves (2004) quando dizem que após elaboração da síntese do conteúdo pelo aluno, este deve voltar a prática social para dessa forma, reelaborar os conceitos apreendidos. Essa prática social pode ser entendida como o próprio 
contexto escolar. Consequentemente, essa relação de feedback é relevante para a (re)construção da informação ainda mais em contextos em que os alunos são distribuídos em grupos para estudo em sala de aula.

Nessa direção, Rose (2016) indica que a cooperação como forma de interação entre os pares promove a aprendizagem mútua e a adoção de novos papéis dentro de um mesmo grupo, fazendo esses estudantes passem a ser ao mesmo tempo ensinadores e aprendizes ao partilhar da estimulação e do auxílio mútuo. E assim sendo, essa colaboração se estabelece ao "discutirem e argumentarem uns com os outros, avaliando os conhecimentos e resolvendo as lacunas de entendimentos com os colegas, tendo em vista que cada um do grupo passe a dominar os conceitos e conteúdos alvo" (p. 308).

Percebemos então que a partir do estudo individual e a partilha do conhecimento com a finalidade de rever e aprimorar o aprendizado, vantagens são adquiridas por meio desse movimento de interação e colaboração entre os alunos e o professor.

A colaboração mútua em uma sala de aula pode agregar e contribuir positivamente em uma reflexão crítica dos conteúdos discutidos entre os atores presentes nesse contexto. Podemos indicar a reflexão crítica como uma tomada de consciência acerca das razões e os motivos para determinado fato, investigando e conhecendo o que é observado, no entanto buscando sempre o olhar de fora. Dessa maneira, deve ser estimulado no processo de aprendizagem a reflexão crítica, atendendo a premissa do estudante autônomo e protagonista.

Nesse sentido Leal e Carmo (2014) destacam a importância dessa perspectiva para o aluno, com vistas a desenvolver as suas potencialidades. E assim sob o aspecto da criticidade, Freire (2015) discorre sobre a inexistência possível de um processo de educação neutra, assim sendo sempre somos influenciados e influenciamos, tanto sendo alunos ou sendo professores. Sob esse olhar, é relevante a reflexão crítica no processo de aprendizagem do estudante, para possibilitar assim uma transformação do seu próprio mundo e o mundo ao seu redor.

Então, percebemos a importância da reflexão crítica pois ela está vinculada a autonomia e protagonismo, mesmo assim temos que refletir sobre nosso próprio aprendizado pois somos bombardeados por informações diariamente, e assim a reflexão crítica é a libertação do estado de inércia.

\subsection{Metodologia Ativa e suas Nuances}

A princípio sobre a metodologia ativa é relevante destacarmos dois pontos. O primeiro é que quando nos referirmos a ela não estamos nos atendo a algo concreto, e sim um conceito que pode ser concebido a partir de alguns parâmetros conceituais. Dessa forma, estes ao serem 
executados na estratégia pedagógica, podem vislumbrar ser ou não uma metodologia ativa, e com isso, se diferenciarem do ensino dito tradicional.

Dessa forma, é necessário a práxis que nas palavras de Freire (2010) se estabelece como um "modo de compreender a existência a partir da relação entre subjetividade e objetividade, entre ação e reflexão" (p. VIII). Nesse sentido então, a partir da interrelação cíclica da teoria-prática, podemos refinar e aprimorar a estratégia pedagógica planejada e executada, a partir dos parâmetros conceituais, surgindo a partir disso, uma metodologia ativa efetivamente aplicada.

E o segundo ponto trata de que exemplos de metodologia ativa efetivamente aplicadas não serão base de observação deste trabalho nos moldes de revisão bibliográfica, pois para tal, há outros trabalhos que enfoquem especificamente esse sentido, citando alguns exemplos de trabalhos como os de: Paiva e Parente et al. (2016); Marques, Campos e Leme (2018); Sobral e Campos (2012); Lovalo e Michelotti et al. (2018); Rückl e Vosgerau (2017); Aragão e Maranhão (2019); Berbel (2011) dentre outros. Esses trabalhos contêm dezenas de exemplos de metodologias ativas implementadas sob diversos cenários.

Enfim, ao se tratar de métodos contemporâneos ao ensino, temos nesse direcionamento a metodologia ativa que que versa por caminho díspar ao ensino tradicional, assim sendo, trataremos um pouco sobre ela.

Quanto ao seu surgimento Lourenço Filho (1978) apresenta que modelos aos quais traziam o aluno ao centro do ensino já despontavam no começo do século XX com a Escola Nova. Muito embora, segundo Bartolomeu, Silva e Lozza (2017) a metodologia ativa surgiu por volta dos fins dos anos de 1990 e tem por característica tornar o estudante o principal responsável em sua aprendizagem. Para isso, deve haver a participação igualitária de todos os atores envolvidos nesse contexto, tendo cada um a consciência de seu papel e com isso possibilitar o "desenvolvimento do senso crítico e a reflexão do aluno sobre diversos temas, exercitando sua autonomia e tornando-o parte integrante de sua produção de conhecimento" (p. 535).

Em seus estudos sobre metodologia ativa, Borges e Alencar (2014) a entendem como formas de desenvolver o processo pelo qual os professores conduzem a formação crítica dos estudantes, e como isso favorece a autonomia, desperta a curiosidade e estimula as tomadas de decisões de forma individual ou em grupo, agora e no futuro.

Sob outro olhar, Pereira (2012) discorre que a metodologia ativa é uma estratégia como por exemplo, sala de aula invertida, gameficação, ensino híbrido, promoção de seminários e discussões, etc., na qual a centralidade desse processo se dá no aluno. De outro modo, isso é antagônico ao proposto pelo ensino tradicional, em que o pensamento exclusivo está na ação intelectual do professor como único saber na sala de aula. 
Percebe-se então que para se colocar em prática a metodologia ativa é necessário um renovo nos processos pedagógicos em que devem envolver os atores do contexto escolar, levando-se em conta, que se o professor não tomar o seu papel como mediador ou o aluno deixar a passividade, pouco resultado positivo haverá. Tendo em vista que nesse cenário, o professor continuará sendo o detentor do conhecimento e o aluno um receptáculo do ensino, mantendo o mesmo status quo presente no ensino dito tradicional.

Dessa forma, e é nesse contexto em que a metodologia ativa se incorpora, pontuando a deficiência do ensino puramente baseado na transmissão de conteúdo em benefício de um ensino ativo, colaborativo, lúdico e inovador em que o aluno tem papel ativo. Nesse cenário, o aluno é protagonista e a construção do conhecimento se dá por meio da interação sob a mediação do professor.

\section{RESULTADOS E DISCUSSÕES}

Levando-se em conta os argumentos acima, com vista a fazer contraponto ao ensino tradicional, a partir de uma metodologia mais atraente, instigante e inovadora para o ensino, podemos elencar pelo menos seis parâmetros conceituais que podem subsidiar estratégias pedagógicas diversas, conforme entendimentos advindos dos autores Berbel (2011), Jófili (2002), Tavares (2019), Mitrulis (2002), Messina (2001), Kishimoto (1996), Vygotsky (1984), Pimenta (2011), Soares (2010), Huizinga (2008), Neves (2014), Inocêncio e Cavalcanti (2007), Oliveira (2010), Freire (2015), Anastasiou e Alves (2004), Rose (2016) e Leal e Carmo (2014). Ei-los abaixo:

1. Autonomia e protagonismo do aluno;

2. Inovação pedagógica;

3. Atividades lúdicas;

4. Professor mediador;

5. Interação e colaboração no grupo;

6. Reflexão crítica da realidade.

A partir desses parâmetros conceituais, percebe-se um claro contrassenso defronte o ensino tradicional. Questionamos então, qual metodologia pode ser guarda-chuva a todas esses parâmetros conceituais aos quais digladiam com o ensino dito tradicional? Como resposta, Peixoto (2016) destaca que como alternativa à prática do ensino tradicional surgiram as metodologias ativas que possibilitam o estudante atuar de maneira mais proativa "na construção de seu conhecimento" (p. 35) e o professor como mediador nesse contexto. 
Dessa forma, elencamos seis parâmetros conceituais - sozinhos ou em conjunto - que podem subsidiar estratégias pedagógicas diversas. À vista disso, analisaremos se eles estão presentes no contexto de metodologia ativa, ou seja, se podem estar sob o guarda-chuva desta.

O primeiro parâmetro conceitual é a autonomia e protagonismo do aluno. No que tange a instigação à autonomia e protagonismo do aluno no contexto de metodologia ativa, percebemos que há uma preocupação nesse sentido e para tal deve ser aplicado diferentes modelos e estratégias para se chegar a esse fim (PAIVA et al., 2016).

Nesse direcionamento, Pinto (2020) considera o aluno como o personagem principal e o maior responsável no processo de aprendizagem, e com isso o objetivo é que se desenvolva a sua capacidade autônoma e participativa. Em consonância a esse pensamento, Garofalo (2018) discorre que a metodologia ativa incentiva ao aluno a partir de problemas e situações reais, com vistas a este ser o centro do ensino e corresponsável pelo seu conhecimento.

O segundo parâmetro conceitual é a inovação pedagógica com a utilização ou não de tecnologias digitais. Essas inovações são propostas para possibilitar que o professor desenvolva novas habilidades de aprendizagem com o seu estudante. No que tange o uso de tecnologias digitais no contexto de metodologia ativa, Moran (2015) dialoga que o contexto digital percorre todos os campos da atividade humana e por consequência, o ensino não poderia se eximir disso.

Assim, o aprender do estudante conectado acontece através de uma interligação simbiótica entre o mundo real e o virtual, muito embora esses espaços não sejam dicotômicos pois se estendem e se entrecruzam hibridamente a todo o momento. E devido essa mescla, a educação formal nos dias atuais tende a ser cada vez mais misturada pois esta acontece em espaços múltiplos do cotidiano ou da sala de aula, por conta disso "o professor precisa seguir comunicando-se face a face com os alunos, mas também digitalmente, com as tecnologias móveis, equilibrando a interação com todos e com cada um" (p. 16).

Ainda sobre a inovação com o uso de tecnologia, Ferrarini, Saheb e Torres (2019) ponderam que se utilizar dos avanços tecnológicos na instituição escolar, independentemente de seu nível ou etapa, haverá significativas transformações por conta que a interação a partir do uso de aparatos digitais é mais atraente para os estudantes. E além disso, o ensino deve se adequar e se apropriar dos avanços tecnológicos ao qual está inserido.

Porém, para Cambraia, Pagani e Benvenutti (2018) não se pode simplesmente inserir a qualquer modo as tecnologias digitais para se fazer o mais do mesmo, e sim implementa-la adequadamente, pois, dessa maneira, potencializará o estudante a aprender a aprender e a reconstruir o seu conhecimento pela colaboração mútua, apoiado pelo papel de mediador assumido pelo professor ao qual contribuirá na "construção de um novo papel para o aluno" (p. 89). 
O terceiro parâmetro conceitual se atrela ao lúdico. No que tange o lúdico no contexto de metodologia ativa, Martins (2018) cita que a utilização de atividades lúdicas contribui no fortalecimento do protagonismo, autonomia e concepção ativa do estudante através de jogos didáticos, possibilitando "uma forma lúdica de promover a aprendizagem e que pode ser aplicada em diversos contextos" (p. 15).

Nesse sentido, integrar o lúdico à prática educativa é uma proposta de ensino que permite se romper a passividade do aluno e com isso aflorar o coletivo e as identidades presentes e futuras, uma vez que há um "entrelace entre os conceitos que, em princípio poderiam viabilizar a prática de atividades pedagógicas por um viés potencialmente lúdico no contexto de sala de aula" (SOUZA; SALVADOR, 2019, p. 11-14)

O quarto parâmetro conceitual é a posição do professor como mediador. No que tange ao agir mediador do professor no contexto de metodologia ativa, Veigas (2019) cita que a metodologia ativa deve promover uma mudança no paradigma do aprendizado, sendo incluídas as relações entre professor e estudante. Nesse cenário, o professor assume o papel de mediador e o estudante será o transformador de seu próprio processo de ensino, e com isso, possibilitando a abertura de espaço à interação e participação dos estudantes como atores partícipes na construção do conhecimento.

Esse pensamento é corroborado por Sarmento, Austrilino e Medeiros (2017) pois utilizarse de metodologia ativa é uma inovação, ao se abrir caminhos para que novas propostas sejam elaboradas e postas em prática, com fins a promover mudanças nas atitudes de estudantes e professores frente ao conhecimento. Essa mudança se desloca da mera memorização tradicional para o desenvolvimento de habilidades e competências de forma ativa, possibilitando que "os estudantes deixem de ser meros espectadores para se tornarem protagonista de sua própria aprendizagem" (p. 35). Nota-se então que na metodologia ativa é necessário que o professor assuma um papel de mediador na aprendizagem, auxiliando o aluno protagonista.

O quinto parâmetro conceitual é a interação e colaboração no grupo. No que tange a interação e colaboração no grupo no contexto de metodologia ativa, Bastos (2006) discorre que essa relação/diálogo - tanto em um nível individual quando coletivo - visa encontrar respostas para determinada situação. E nesse caso, o professor como mediador, também está envolto nessa condução da prática, as quais devem se apresentar questões globais como também locais em consonância com o perfil do contexto ao qual esse grupo está inserido.

Esse pensamento se alinha ao de Garofalo (2019) ao descrever que a aprendizagem colaborativa é uma forma efetiva de constituir um ensino envolvente, ativo e significativo para o estudante. Uma vez que a metodologia que possibilita o desenvolvimento a partir de grupos de trabalho debruçados sobre um problema real, valoriza os conhecimentos prévios e o 
compartilhamento de saberes individuais do estudante e coletivo que o mesmo se apropriou através do contato com o seu contexto social.

Além disso, o trabalho coletivo traz uma construção de respeito e a empatia mútua, com vista a se chegar a um consenso. Assinala-se então que a metodologia ativa não é apenas um único ato, e sim, diversos processos interativos que reforçam o conhecimento, análise e soluções para um problema, tanto individual como também através da interação e colaboração do grupo ao qual o estudante está envolvido.

O sexto parâmetro conceitual é a reflexão crítica da realidade. No que tange à reflexão crítica da realidade no contexto de metodologia ativa, podemos deduzir que estas reforçam o processo de aprendizagem através da realização de atividades práticas, reais ou simuladas. Nesse sentido Berbel (2011) cita que as metodologias ativas devem utilizar-se da simulação visando "às condições de solucionar com sucesso, desafios advindos das atividades essenciais da prática social em diferentes contextos" (p. 29).

Ademais, as metodologias ativas tem potenciais para ressignificar e ampliar as possibilidades de escolhas nas tomadas de decisões pois estas se utilizam da problematização como uma estratégia de ensino para motivar o estudante, uma vez que este se pondo diante de um problema, irá se deter, refletir, examinar a partir de seus conhecimentos prévios com fins a ressignificar sua descoberta. E dessa forma ao problematizar a situação posta, produzirá conhecimento ao qual lhe será útil para aqueles e para futuras situações em seu desenvolvimento enquanto sujeito social, posto que novas aprendizagens são instrumentos primordiais e significativos para "ampliar suas possibilidades e caminhos, esse poderá exercitar a liberdade e a autonomia na realização de escolhas e na tomada de decisões" (MITRE et al., 2008, p. 2136).

Temos então que, em vista dos argumentos acima levantados, podemos concluir que os parâmetros conceituais propostos em contraponto à educação ditas como tradicional, podem subsidiar estratégias pedagógicas diversas no contexto da metodologia ativa. Sendo que, não é necessário que todos os parâmetros conceituais estejam presentes tendo em vista suas interdependências, pois podemos ter estratégias baseadas em um, dois ou mais parâmetros conceituais, isso a depender do contexto local ou da finalidade à qual a aula é pensada.

Muito embora tenhamos tratado em se contrapor a educação dita tradicional, sabemos que na educação brasileira ainda predomina essa visão, mas diante do avanço da tecnologia e mudanças de paradigmas que ocorrem com o passar do tempo, o contexto das metodologias ativas pode se fazer mais presente no dia a dia das escolas.

Nesse sentido, uma ruptura que dividisse abruptamente a prática tradicional às metodologias ativas não seria possível hoje, primeiramente por todas as bases de formação de 
professores e também adequação dos alunos a essas estratégias demandaria um tempo, dentre outros fatores, dessa forma, é necessário que essa transição ocorra gradualmente. E como saída a isso, consideramos que a partir das aulas tradicionais, estratégias do contexto da metodologia ativa podem ser inseridas pontualmente, e com o passar do tempo sua implementação seria posta em prática mais frequentemente.

Outrossim, é necessário destacar que esses dois paradigmas educacionais - ensino tradicional e metodologias ativas - não são excludentes entre si e nem dicotômicos aos extremos para que se exigisse a abolição completa de um em proveito do outro. Ao invés disso, poderia se propor um entremeio no qual elementos dos dois modelos se entrelacem com fins a um ensino mais diversificado, como o é, o agrupamento heterogêneo de estudantes dentro de qualquer sala de aula.

Percebe-se então que à prática docente, é possível haver tanto aulas meramente expositivas quanto aquelas alinhadas ao contexto da metodologia ativa, isso a depender do que se propôs no planejamento. Ademais, essa comunhão entre esses paradigmas pode ser considerada a partir de um olhar sobre o nosso país, onde as condições sociais-econômicas da população, a formação docente e de infraestrutura, são em grande parte deficitárias e discrepantes entre si.

\section{CONSIDERAÇÕES FINAIS}

Por meio desta pesquisa identificamos seis parâmetros conceituais que podem subsidiar estratégias pedagógicas diversas no contexto de metodologia ativa, os quais são: autonomia e protagonismo do aluno; inovação nas práticas pedagógicas; atividades lúdicas; professor mediador; interação e colaboração no grupo; e, reflexão crítica da realidade. E como conclusão deste estudo, apresentamos esses parâmetros conceituais como subsidiários à construção e desenvolvimento de estratégias pedagógicas no contexto de metodologia ativa, tendo em vista, essa necessidade advinda dos dias atuais, ao qual se estimulam métodos inovadores e diversificados à ação educativa, sendo esta, nossa questão investigativa.

Ademais como observações complementares advindas desse estudo destacamos que o ensino tradicional é predominante no Brasil muito embora sua eficácia seja questionada a algum tempo, e por conta disso outros contextos de ensino foram aventados, como no caso da metodologia ativa. A esta, se atribuiu novos papéis tanto ao aluno como ao professor, deixando o primeiro de ser passivo para ser ativo e o segundo, de detentor para mediador do conhecimento.

Além disso, se apresentou que a metodologia ativa não seria necessariamente tão recente pois encontra similitudes com as orientações pertinentes à Escola Nova que surgiu no século XIX, 
mas chegou ao Brasil no início do século XX. Ademais, há de se destacar que os parâmetros conceituais identificados nesta pesquisa podem ser utilizados de forma independente como também em conjunto no contexto da metodologia ativa, uma vez que eles se interrelacionam e podem construir estratégias mais dinâmicas e atrativas ao estudante.

Também não pretendemos abolir o ensino tradicional em prol das metodologias ativas, pois estes podem ser dosados e utilizados de acordo com o propósito do planejamento das aulas dos professores, pois os alunos de uma sala de aula são heterogêneos, então cada um pode ter uma forma diferenciada ao qual se apropria melhor do conhecimento, pois uns podem aprender melhor ouvindo, outros escrevendo, outros lendo e assim sucessivamente. Muito embora, consideramos que o uso deve ser predominantemente de contextos de metodologia ativa para que haja resultados mais satisfatórios para o aprendizado, com pitadas de ensino tradicional. E para que isso se ponha em prática nos dias atuais, essa mescla deve ser aplicada progressivamente com vista a se chegar em um ponto de equilíbrio.

Logo, entendemos que nossos resultados corroboram autores como Berbel (2011), Jófili (2002), Tavares (2019), Mitrulis (2002), Messina (2001), Kishimoto (1996), Vygotsky (1984), Pimenta (2011), Soares (2010), Huizinga (2008), Neves (2014), Inocêncio e Cavalcanti (2007), Oliveira (2010), Freire (2015), Anastasiou e Alves (2004), Rose (2016) e Leal e Carmo (2014), aos quais destacam sob diversos prismas, que o uso dos parâmetros conceituais (autonomia e protagonismo do aluno; inovação nas práticas pedagógicas; atividades lúdicas; professor mediador; interação e colaboração no grupo; e, reflexão crítica da realidade) no contexto de metodologia ativa, contribui para o aprendizado dos estudantes. Essa contribuição pode se dar individualmente ou coletivamente pelo aluno, fazendo com que a partir de seus conhecimentos prévios, ele se detenha, reflita, busque e examine, ressignificando assim sua descoberta.

Por fim, indicamos para estudos futuros dois pontos, os quais são relacionados a este trabalho, mas não foram seu foco. O primeiro trata de questões que permeiam a própria formação docente para apreender e aplicar esse modelo mais lúdico e criativo, e o segundo se põe a analisar as discussões que permeiam as próprias condições socioeconômicas dos estudantes que podem ter certas restrições de acesso a determinado aparatado digitais que seria necessário para essas atividades. Sendo assim, a partir dessas questões apresentadas acima, temos um longo caminho ainda a trilhar...

\section{REFERÊNCIAS}

ANASTASIOU, L. D. G. C.; ALVES, L. P. Estratégias de ensinagem. In: Processos de ensinagem na Universidade. Pressupostos para estratégias de trabalho em aula. 3. ed. 
Joinville: Univille, 2004. Cap. 3, p. 67-100. Disponível em: <https://moodle.ufsc.br/pluginfile.php/1390223/mod_resource/content/1/anastasiou.pdf $>$. Acesso em: 01 jun. 2020.

ARAGÃO, E.; MARANHÃO, R. V. Estudos Sobre o Uso Da Metodologia Ativa no Ensino Superior do Brasil: Uma Revisão Bibliográfica. Revista Ciências da Saúde e Educação, Formosa-GO, v. 1, n. 2, p. 1-15, 2019.

BARTOLOMEU, T. D. F.; SILVA, H. Z. S. D.; LOZZA, S. I. Metodologias Ativas: um Caminho Para Inovar as Práticas Pedagógicas. Caderno PAIC, Curitiba, v. 18, n. 1, p. 560-574, 2017. Disponível em: < https://cadernopaic.fae.edu/cadernopaic/article/view/247/229>. Acesso em: 8 abr. 2021.

BASTOS, C. D. C. Educação \& Medicina. Metodologias Ativas, 2006. Disponível em: $<$ http://educacaoemedicina.blogspot.com/2006/02/metodologias-ativas.html >. Acesso em: 30 mai 2020 .

BEHAR, P. A. A validação de objetos de aprendizagem para formação de professores de Educação Infantil. CINTED-UFRGS. Novas Tecnologias na Educação, Porto Alegre, v. 6, n. 1, p. 1-11, jul 2008.

BERBEL, N. A. N. As metodologias ativas e a promoção da autonomia de estudantes. Semina: Ciências Sociais e Humanas, Londrina, v. 32, n. 1, p. 25-40, jan./jun. 2011. ISSN 10.5433/16790359 .

BORGES, T. S.; ALENCAR, G. Metodologias ativas na promoção da formação crítica do estudante: o uso das metodologias como recurso didático na formação crítica do estudante do ensino superior. Cairu em Revista, São João del-Rei, v. 4, p. 119-143, jul./ago. 2014. Disponível em: $<$ http://www.ufsj.edu.br/portal2repositorio/File/napecco/Metodologias/Metodologias $\% 20$ Ativas\%20na\%20Promocao\%20da\%20Formacao.pdf>. Acesso em: 8 abr. 2021.

BRASIL. Constituição da República Federativa do Brasil: promulgada em 5 de outubro de 1988, $1988 . \quad$ Disponível em: <http://www.planalto.gov.br/ccivil_03/constituicao/constituicao.htm>. Acesso em: 14 maio 2020.

BRASIL. Lei no 9.394 de 20 de dezembro de 1996. Estabelece as diretrizes e bases da educação nacional., 1996. Disponível em: <http://www.planalto.gov.br/ccivil_03/leis/19394.htm>. Acesso em: 16 maio 2020.

BRASIL. MEC. Base Nacional Comum Curricular, 2018. Disponível em: $<$ http://basenacionalcomum.mec.gov.br/images/BNCC_EI_EF_110518_versaofinal_site.pdf $>$. Acesso em: 06 fev. 2020. 
CAMBRAIA, A. C.; PAGANI, L. M.; BENVENUTTI. Metodologias ativas e tecnologias digitais na formação do professor de computação. Revista Brasileira de Ensino de Ciências e Matemática - RBECM, Passo Fundo, v. 1, n. 1, p. 85-98, jan./jun. 2018.

CAROLEI, P.; BRUNO, G. D. S.; ROCHA, N. R. B. C. Controvérsias entre recurso e estratégia pedagógica no discurso sobre a adoção de jogos eletrônicos no ensino de ciências. XI Encontro Nacional de Pesquisa em Educação em Ciências - XI ENPEC. Florianópolis, p. 1-10. 2017.

COSTA, S. R. S.; DUQueviZ, B. C.; PEDROZA, R. L. S. Tecnologias Digitais como instrumentos mediadores da aprendizagem dos nativos digitais. Revista Quadrimestral da Associação Brasileira de Psicologia Escolar e Educacional, São Paulo-SP, v. 19, n. 3, p. 603610, set/dez 2015. ISSN 10.1590/2175-3539/2015/0193912. Disponível em: <https://www.scielo.br/pdf/pee/v19n3/2175-3539-pee-19-03-00603.pdf>. Acesso em: 28 maio 2020 .

ENGUITA, M. F. Educar em tempos incertos. Tradução Fátima Murad. Porto Alegre: Artmed, 2004.

FERRARINI, R.; SAHEB, D.; TORRES, P. L. Metodologias ativas e tecnologias digitais: aproximações e distinções. Revista Educação em Questão, Natal, v. 57, n. 52, p. 1-30, abr./jun. 2019. ISSN 10.21680/1981-1802.2019v57n52ID15762.

FREIRE, P. Pedagogia da Autonomia. Saberes necessários à prática educativa. 51. ed. Rio de Janeiro: Paz e terra, 2015.

FREIRE, P. S. Pedagogia da práxis: o conceito do humano e da educação no pensamento de Paulo Freire. Dissertação de Mestrado - Universidade Federal de Pernambuco. Recife-PE, p. 188. 2010.

GAROFALO, D. Nova Escola. Como as metodologias ativas favorecem o aprendizado, 2018. Disponível em: <https://novaescola.org.br/conteudo/11897/como-as-metodologias-ativasfavorecem-o-aprendizado>. Acesso em: 31 maio 2020.

GAROFALO, D. Nova Escola. Como envolver os alunos na aprendizagem colaborativa, 2019. Disponível em: <https://novaescola.org.br/conteudo/16167/como-envolver-os-alunosna-aprendizagem-colaborativa $>$. Acesso em: 31 maio 2020.

GIL, A. C. Como elaborar projetos de pesquisa. 4. ed. São Paulo: Atlas, 2002.

HUIZINGA, J. Homo Ludens. 5. ed. São Paulo: Perspectiva, 2008. Disponível em: <http://jnsilva.ludicum.org/Huizinga_HomoLudens.pdf>. Acesso em: 01 jun. 2020. 
INOCENCIO, D.; CAVALCANTI, C. M. C. O papel do professor como mediador do processo de ensino-aprendizagem em ambientes on-line. Cad. psicopedag., São Paulo, v. 6, n. 11, p. 1-19, 2007.

JÓFILI, Z. Piaget, Vygotsky, Freire e a construção do conhecimento na escola. Educação: Teorias e Práticas, Recife, v. 2, n. 2, p. 191-208, dez 2002.

KENSKI, V. M. O papel do professor na sociedade. In: CARVALHO, A. M. P. D.; CASTRO, A. D. D. Ensinar a Ensinar. São Paulo: Pioneira, 2001. p. 226.

KISHIMOTO, T. M. Jogo, brinquedo, brincadeira e a educação. 7. ed. São Paulo: Cortez, 1996.

LEAL, M. L.; CARMO, M. F. D. Bases e Fundamentos da Socioeducação. In: MEDEIROS, A. Docência na socioeducação. Brasília: Universidade de Brasília, Campus Planaltina, 2014. p. 348.

LIBÂNEO, J. C.; OLIVEIRA, J. F. D.; TOSCHI, M. S. Educação Escolar: políticas, estrutura e organização. São Paulo: Cortez, 2003.

LOURENÇO FILHO, M. B. Introdução ao estudo da Escola Nova. 13. ed. São Paulo: Edições Melhoramentos, 1978.

LOVATO, F. L. et al. Metodologias Ativas de Aprendizagem: uma Breve Revisão. Acta Scientiae, Canoas, v. 20, n. 2, p. 154-171, mar./abr. 2018.

MARQUES, H. R.; CAMPOS, A. C.; LEME, P. H. M. V. Metodologias Ativas de Ensino Aprendizagem: uma revisão sistemática da literatura. XXI SEMEAD Seminários em Administração. São Paulo: [s.n.]. 2018. p. 1-17.

MARTINS, L. Jogos Didáticos Como Metodologia Ativa no Ensino de Ciências. Trabalho de Conclusão de Curso, do Instituto Federal de Santa Catarina Câmpus Jaraguá do Sul (IFSC, SC). Jaraguá do Sul, p. 77. 2018.

MARTINS, C.; GIRAFFA, L. M. M.; LIMA, V. M. D. R. Gamificação e seus potenciais como estratégia pedagógica no Ensino Superior. RENOTE - Revista Novas Tecnologias na Educação, Porto Alegre, v. 16, n. 1, p. 1-10, jul. 2018. Acesso em: 09 set. 2021.

MESSINA, G. Mudança e inovação educacional: notas para reflexão. Cad. Pesqui., São Paulo, n. 114, p. 225-233, nov. 2001. Disponível em: $<$ http://www.scielo.br/scielo.php?script=sci_arttext\&pid=S0100-

15742001000300010\&lng=en\&nrm=iso >. Acesso em: 01 jun. 2020.

MITRE, S. M. et al. Metodologias ativas de ensino-aprendizagem na formação profissional em saúde: debates atuais. Ciênc. saúde coletiva, Rio de Janeiro, v. 13, n. 2, p. 2133-2144, dez 2008. 
MITRULIS, E. Ensaios de inovação no ensino médio. Cadernos de Pesquisa, São Paulo, n. 116, p. 217-244, jul 2002. Disponível em: <https://www.scielo.br/pdf/cp/n116/14404.pdf>. Acesso em: 01 jun 2020.

MORÁN, J. Mudando a educação com metodologias ativas. In: (ORGS.)., C. A. D. S. E. O. E. T. M. Coleção Mídias Contemporâneas. Convergências Midiáticas, Educação e Cidadania: aproximações jovens. Vol. II. Ponta Grossa: [s.n.], v. 2, 2015. p. 15-33. Disponível em: <http://www2.eca.usp.br/moran/wp-content/uploads/2013/12/mudando_moran.pdf>.

Acesso em: 31 maio 2020.

MORIN, E. Introdução ao pensamento complexo. 3. ed. Porto Alegre: Sulina, 2007.

NEVES, D. T. Formação de Professores: O Papel do Professor-Mediador. ENEPE - Encontro de Ensino, Pesquisa e Extensão (UNOESTE). Presidente Prudente: [s.n.]. 2014. p. 887-93.

OLIVEIRA, E. G1. Estados adotam plataformas online e aulas na TV aberta para levar conteúdo a estudantes em meio à pandemia de coronavírus, 2020. Disponível em: <https://g1.globo.com/educacao/noticia/2020/04/09/estados-adotam-plataformas-online-eaulas-na-tv-aberta-para-levar-conteudo-a-estudantes-em-meio-a-pandemia-decoronavirus.ghtml>. Acesso em: 22 maio 2020.

OLIVEIRA, L. A. Coisas que todo professor de português precisa saber: a teoria na prática. São Paulo: Parábola Editorial, 2010.

PAIVA, M. R. F. et al. Metodologias ativas de ensino-aprendizagem: revisão integrativa. SANARE - Revista de Políticas Públicas, Sobral-CE, v. 15, n. 2, p. 145-153, jun./dez. 2016.

PARADA, E. A. TICs na escola: balanço de teses e dissertações brasileiras produzidas no período de 1990 a 2010. Dissertação (Mestrado em Educação) Programa de Pós-Graduação em Educação: Currículo, Pontifícia Universidade Católica de São Paulo/PUC-SP. São Paulo, p. 137. 2011.

PEIXOTO, A. G. O Uso de Metodologias Ativas Como Ferramenta de Potencialização da Aprendizagem de Diagramas de Caso de Uso. Periódico Científico Outras Palavras, Brasília, v. 12, n. 2, 2 p. 35-50, 2016. Disponível em: $<$ http://revista.faculdadeprojecao.edu.br/index.php/Projecao5/article/view/718/604>. Acesso em: 8 abr. 2021.

PEREIRA, R. Método Ativo: Técnicas de Problematização da Realidade aplicada à Educação Básica e ao Ensino Superior. VI Colóquio internacional. Educação e Contemporaneidade. São Cristóvão, SE, p. 1-15. 2012. 
PIMENTA, J. G. A Importância dos Jogos e Brincadeiras na Educação Infantil. Monografia - Lato Sensu em Educação Infantil e Desenvolvimento (Universidade Candido Mendes). Rio de Janeiro, p. 41. 2011.

PINTO, D. D. O. Lyceum. Metodologias Ativas de Aprendizagem: o que são e como aplicálas, 2020. Disponível em: <https://blog.lyceum.com.br/metodologias-ativas-de-aprendizagem/>. Acesso em: 31 maio 2020.

REIS, G.; OLIVEIRA, J. F. D. PUC. A Constituição do Currículo Escolar no Brasil: Dilemas, Impasses e Perspectivas, 2018. Disponível em: <https://sites.pucgoias.edu.br/posgraduacao/mestrado-doutorado-educacao/wp-content/uploads/sites/61/2018/05/GeovanaReis_-Joao-Ferreira-de-Oliveira.pdf>. Acesso em: 16 abr. 2021.

ROSE, T. M. S. D. et al. Práticas Educativas Inovadoras na Formação do Psicólogo Escolar: uma Experiência com Aprendizagem Cooperativa. Psicologia: Ciência e Profissão, Brasília, v. 36, n. 2, p. 304-316, jun. 2016.2 Disponível em: $<$ http://www.scielo.br/scielo.php?script=sci_arttext\&pid=S1414-

98932016000200304\&lng=en\&nrm=iso >. Acesso em: 01 jun. 2020.

RÜCKL, B. D. F. N.; VOSGERAU, D. S. R. Perspectivas da Aprendizagem Ativa no Ensino Fundamental: Uma Revisão Sistemática. EDUCERE - XIII Congresso Nacional de Educação. Curitiba: [s.n.]. 2017. p. 11883-11901.

SANTOS, P. T. D.; KELMAN, C. A. Estratégias Pedagógicas no Ensino de Português Como Segunda Língua. IV Congresso Brasileiro Multidisciplinar de Educação Especial. Londrina, p. 18. 2007.

SARMENTO, A. S. T. L.; AUSTRILINO, L.; MEDEIROS, M. L. Metodologias ativas no processo ensino aprendizagem na área de neurologia. Conhecimento \& Diversidade, Niterói, v. 9, n. 19, p. 27-36, out./dez. 2017.

SAVIANI, D. Escola e democracia. 24. ed. São Paulo: Cortez, 1991.

SILVA, T. D. O.; SILVA, L. T. G. Os impactos sociais, cognitivos e afetivos sobre a geração de adolescentes conectados às tecnologias digitais. Rev. psicopedag., São Paulo, v. 34, n. 103, p. 8797, 2017. Disponível em: <http://pepsic.bvsalud.org/scielo.php?script=sci_arttext\&pid=S010384862017000100009\&lng=pt\&nrm=iso $>$. Acesso em: 28 maio 2020.

SIQUEIRA, F. A. R.; QUIRINO, A. C. D. S. O Ensino de História nas Séries Iniciais do Ensino Fundamental: Metodologias e Práticas Pedagógicas. IV FIPED - Fórum Internacional de Pedagogia. Parnaíba-PI: Editora Realize. 2012. p. 1-12.

SOARES, E. M. http://www.ffp.uerj.br. A ludicidade no processo de inclusão de alunos especiais no ambiente educacional, 2010. Disponível em: 
<http://www.ffp.uerj.br/arquivos/dedu/monografias/EMS.2.2010.pdf>. Acesso em: 05 fev. 2020.

SOBRAL, F. R.; CAMPOS, C. J. G. Utilização de metodologia ativa no ensino e assistência de enfermagem na produção nacional: revisão integrativa. Revista da Escola de Enfermagem da USP, São Paulo, v. 46, n. 1, p. 293-301, 2012.

SOUZA, J. M. P. D.; SALVADOR, M. A. S. O lúdico e as metodologias ativas: possibilidades e limites nas ações pedagógicas. 1. ed. Rio de Janeiro: Imperial, 2019.

TACCA, M. C. Aprendizagem e trabalho pedagógico. 3. ed. Campinas, SP: Editora Alínea, 2014.

TAVARES, F. G. D. O. O conceito de inovação em educação: uma revisão necessária. Educação (UFSM), Santa Maria, v. 44, p. 1-19, fev. 2019. Disponível em: <https://periodicos.ufsm.br/reveducacao/article/view/32311>. Acesso em: 01 jun. 2020.

VIEGAS, A. SomosPar. Metodologias Ativas: Como essa tendência pode beneficiar as práticas pedagógicas? 2019. Disponível em: < https://www.somospar.com.br/metodologias-ativas-comoessa-tendencia-pode-beneficiar-as-praticas-pedagogicas/>. Acesso em: 31 maio 2020.

VYGOTSKY, L. S. A formação social da mente. São Paulo: Martins Fontes, 1984. 